\title{
Analisis Rugi-Rugi (Losses) Transformator Daya 150/20 KV di PT. PLN (Persero) Gardu Induk Sutami ULTG Tarahan
}

\author{
Hendri Elnizar ${ }^{1}$, Herri Gusmedi², Osea Zebua ${ }^{3}$ \\ Jurusan Teknik Elektro Universitas Lampung, Bandar Lampung \\ Jl. Prof. Sumantri Brojonegoro No.1 Bandar Lampung 35145 \\ hendrielnizarregmail. $\mathrm{com}^{1}$ \\ herri.gusmedideng.unila.ac.id ${ }^{2}$ \\ osea. zebuadeng.unila.ac.id ${ }^{3}$
}

Intisari - Pada umumnya, dalam penyaluran energi listrik, akan selalu terdapat rugi-rugi (losses). Pada transformator terdapat dua jenis rugi-rugi yaitu rugi-rugi teknis dan rugi-rugi non-teknis. Rugi-rugi non-teknis disebabkan oleh hal-hal diluar kinerja sistem, seperti kecelakaan, bencana alam, kelalaian manusia, dan sebagainya. Sedangkan rugi-rugi teknis disebabkan oleh dua hal, yaitu rugi-rugi tembaga (copper losses) dan rugi-rugi inti besi (core losses). Rugi-rugi teknis pada trafo menyebabkan efesiensi penyedia tenaga listrik menjadi rendah. Oleh karena itu penulis akan membuat skripsi yang berjudul "Analisis Rugi-rugi (Losses) Transformator Daya 150/20 KV di PT.PLN (PERSERO) Gardu Induk Sutami ULTG Tarahan" Analisis dilakukan pada bulan Juli 2019, yang bertujuan untuk mengetahui besarnya rugi-rugi pada transformator setiap hari dalam waktu satu bulan, serta menghitung persentase kenaikan losses terhadap perubahan arus beban normal ke arus beban puncak. Hasil perhitungan menunjukkan Losses tertinggi pada Trafo 1 jatuh pada tanggal 23 Juli 2019, sebesar 4.588.204 kw. Losses tertinggi pada Trafo 2 jatuh pada tanggal 11 Juli 2019, sebesar 16.246.884 kw. Kemudian besar perubahan kenaikan arus dari arus beban normal ke arus beban puncak pada Trafo 1, akan menyebabkan losses naik sebesar 3,66\%, dan besar perubahan kenaikan arus dari arus beban normal ke arus beban puncak pada Trafo 2, akan menyebabkan losses naik sebesar 2,38\%.

Kata Kunci: Transformator, losses, copper losses, core losses

Abstract - In general, in the distribution of electrical energy, there will always be losses. In a transformer, there are two types of losses, namely technical losses and non-technical losses. Non-technical losses are caused by things outside of system performance, such as accidents, natural disasters, human negligence, and so on. Meanwhile, technical losses are caused by two things, namely copper losses and core losses. Technical losses in the transformer cause the efficiency of the electricity supply to be low. Therefore the author will make a thesis entitled "Analysis of Losses Power Transformer 150/20 KV in PT PLN (PERSERO) Substation Sutami ULTG Tarahan" The analysis was carried out in July 2019, which aims to determine the amount of losses - losses on the transformer every day within a month, as well as calculating the percentage increase in losses due to changes in normal load current to peak load current. The calculation results show that the highest Losses on Transformer 1 falls on July 23, 2019, amounting to 4,588,204 kw. The highest loss on Transformer 2 falls on July 11, 2019, amounting to $16,246,884 \mathrm{kw}$. Then the magnitude of the change in the increase in current from normal load current to peak load current on Transformer 1, will cause losses to increase by $3.66 \%$, and the amount of change in the increase in current from normal load current to peak load current on Transformer 2, will cause losses to increase by $2,38 \%$.

Keywords: Transformer, losses, copper losses, core losses 


\section{PENDAHULUAN}

Analisis aliran daya merupakan salah satu studi dalam melakukan perhitungan susut daya pada sistem tenaga listrik. Analisa aliran daya sangat penting dilakukan, terutama dalam menyelidiki permasalahan pada sistem operasi dan perencanaan sistem tenaga listrik. Berdasarkan nilai dari suatu generator dan struktur transmisi jaringan listrik, maka dapat menentukan nilai tegangan, arus, dan aliran daya pada setiap titik percabangan pada jaringan listrik dengan melakukan perhitungan analisa aliran daya [1].

Pada zaman dengan teknologi yang semakin pesat dan pertambahan populasi penduduk, maka kebutuhan listrik akan semakin meningkat, sehingga dibutuhkan pemasangan jaringan listrik yang semakin meluas dan permintaan daya listrik yang semakin besar. Dalam hal ini, analisa aliran daya merupakan salah satu solusi utama dalam menentukan perencanaan sistem tenaga listrik kedepan.

Pada umumnya, dalam penyaluran energi listrik, akan selalu terdapat rugi-rugi (losses). Pada transformator terdapat dua jenis rugi-rugi yaitu rugi-rugi teknis dan rugi-rugi non-teknis. Rugi-rugi non-teknis disebabkan oleh hal-hal diluar kinerja sistem, seperti kecelakaan, bencana alam, kelalaian manusia, dan sebagainya. Sedangkan rugi-rugi teknis disebabkan oleh dua hal, yaitu rugi-rugi tembaga (copper losses) dan rugi-rugi inti besi (core losses). Rugi-rugi teknis pada trafo menyebabkan efesiensi penyedia tenaga listrik menjadi rendah.

Oleh karena itu, penulis akan menganalisis rugi-rugi teknis transformator dengan melakukan perhitungan analisis susut daya dan energi (losses) transformator di GI Sutami, yang dilakukan pada bulan Juli 2019, dikarenakan terdapat losses energi yang tinggi pada bulan tersebut.

Penulis juga akan menganalisis aliran daya pada transformator di GI Sutami menggunakan Microsoft excel untuk dapat mengetahui besarnya susut daya (losses) setiap hari dalam satu bulan pada transformator.
A. Transformator Daya

Dalam IEC 60076-1 Transformator daya didefinisikan sebagai bagian statis aparatur dengan dua atau lebih gulungan dengan induksi elektromagnetik, mengubah sistem bolak-balik tegangan dan arus ke sistem lain yang tegangan dan arus biasanya memiliki nilai yang berbeda dan pada frekuensi yang sama untuk tujuan transmisi tenaga listrik [11].Transformator memiliki konstruksi dan simbol seperti pada gambar berikut ini.

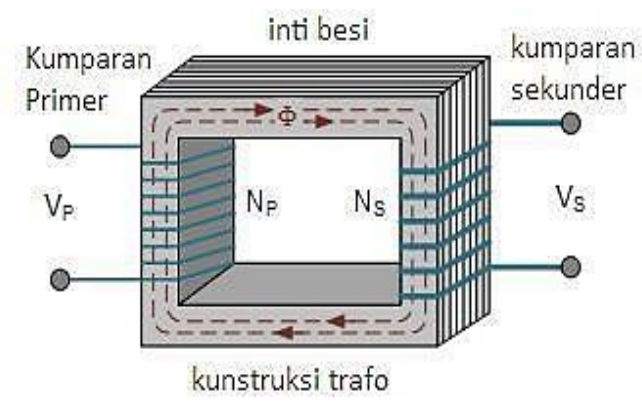

Gbr. 1 Konstruksi transformator

Keterangan dari gambar 1:

$\mathrm{N}_{\mathrm{P}}$ : jumlah lilitan primer

$\mathrm{N}_{\mathrm{S}}$ : jumlah lilitan sekunder

$\mathrm{V}_{\mathrm{P}}$ : tegangan primer

$\mathrm{V}_{\mathrm{S}}$ : tegangan sekunder

Berdasarkan IEV (International Electrotechnical Vocabulary) 441-14-20 disebutkan bahwa circuit breaker (CB) atau Pemutus Tenaga (PMT) merupakan peralatan saklar / switching mekanis, yang mampu menutup, mengalirkan dan memutus arus beban dalam kondisi normal serta mampu menutup, mengalirkan (dalam periode waktu tertentu) dan memutus arus beban dalam spesifik kondisi abnormal / gangguan seperti kondisi short circuit / hubung singkat [2].

Fungsi utamanya adalah sebagai alat pembuka atau penutup suatu rangkaian listrik dalam kondisi berbeban, serta mampu membuka atau menutup saat terjadi arus gangguan ( hubung singkat ) pada jaringan atau peralatann lain. 


\section{B. Bagian-bagian Transformator}

1) Inti Besi

Inti besi berfungsi untuk mempermudah jalan fluksi, yang ditimbulkan oleh arus listrik yang melalui kumparan. Inti besi ini terbuat dari lempengan lempengan besi tipis terisolasi, untuk mengurangi panas (sebagai rugi rugi besi) yang ditimbulkan oleh arus eddy.

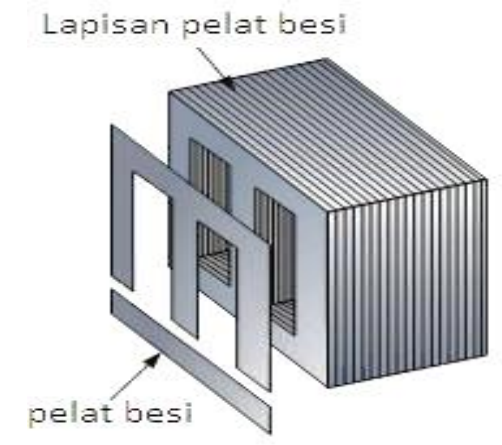

Gbr.2 Inti Besi Transformator

2) Kumparan Transformator

Kumparan trafo adalah beberapa lilitan kawat berisolasi akan membentuk suatu kumparan. Kumparan itu diisolasi baik terhadap inti besi maupun terhadap kumparan lain dengan isolasi padat seperti karton, pertinax dan lain lain.

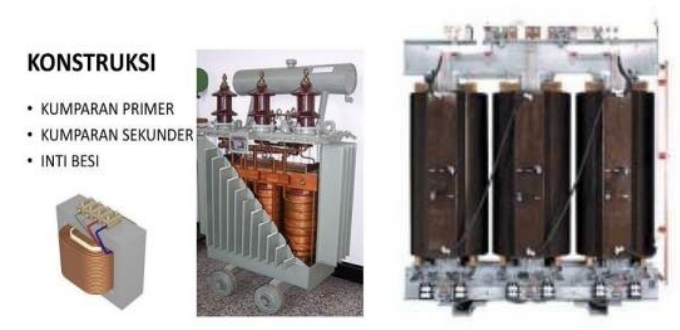

Gbr.3 Kumparan Transformator

Umumnya pada trafo terdapat kumparan primer dan kumparan sekunder. Bila kumparan primer dihubungkan dengan tegangan/arus bolak balik maka pada kumparan tersebut timbul fluksi. Fluksi ini akan menginduksikan tegangan, dan bila pada rangkaian sekunder ditutup maka akan menghasilkan arus pada kumparan ini. Jadi kumparan sebagai alat transformasi tegangan arus.

\section{Rugi-rugi pada Transformator}

Dasar ketika energi listrik yang masuk ke transformator tidak akan sama dengan energi listrik yang akan dikeluarkan dari transformator. Hal tersebut disebabkan adanya rugi - rugi yaitu adanya arus yang hilang saat melewati trafo tersebut. Rugi-rugi tersebut dapat dibagi menjadi dua yaitu : rugi inti $\left(P_{\text {core }}\right)$ dan rugi tembaga $\left(P_{\text {copper}}\right)$.

Ketika kondisi beban nol atau tidak berbeban, rugi - rugi yang didapat hanya rugi inti saja. perubahan beban tidak mempengaruhi rugi inti. Besarnya rugi inti ketika dari beban nol sampai beban penuh nilainya akan terus sama.

Secara umum total rugi-rugi pada transformator dirumuskan pada persamaan berikut :

$$
\text { Plosses }=\mathbf{P}_{\text {copper }}+\text { Pcore }
$$

Dimana :

$\mathbf{P}_{\text {losses }}=$ Total Rugi-rugi transformator (W)

$\mathbf{P}_{\text {copper }}=$ Rugi-rugi kumparan transformator $(\mathrm{W})$

$\mathbf{P}_{\text {core }}=$ Rugi-rugi Inti besi transformator (W)

\section{Rugi-rugi Tembaga (copper losses)}

Rugi-rugi yang disebabkan oleh arus mengalir pada kawat tembaga. Rugi-rugi tembaga akan berbanding lurus dengan besarnya beban sehingga meningkatnya arus beban akan meningkatkan rugi-rugi tembaga juga. Rugi - rugi ini dapat ditulis sebagai berikut [3]:

$$
P_{c u}=I^{2} P \cdot R_{1}+I^{2} s \cdot R_{2}
$$

Dimana :

$\boldsymbol{P}_{\boldsymbol{c u}}=$ rugi - rugi tembaga $($ watt)

$\boldsymbol{I}_{\mathrm{p}}=\operatorname{arus} \operatorname{primer}(\mathrm{A})$

$\boldsymbol{I}_{\mathrm{S}}=\operatorname{arus}$ sekunder $(\mathrm{A})$

$\boldsymbol{R}_{1}=$ resistansi kumparan primer $(\Omega)$

$\boldsymbol{R}_{2}=$ resistansi kumparan sekunder $(\Omega)$

Perumusan ini diatas diperuntukkan hanya sebagai pendekatan. Disebabkan arus beban yang terus mengalami perubahan, rugi tembaga juga tidak konstan karena tergantung pada nilai beban. 


\section{E. Rugi-rugi Inti Besi (core losses)}

Rugi inti pada transformator dibagi atas dua bagian, yaitu rugi hysteresis dan arus eddy yang dapat diukur melalui percobaan/test tanpa beban,dimana pada saat tanpa beban rugi hysteresis yaitu rugi yang disebabkan oleh fluks bolak-balik pada inti besi, sedangkan rugi arus eddy [4], yaitu rugi yang disebabkan oleh arus pusar pada inti besi. Jadi rugi inti dapat ditulis dalam persamaan:

$$
P_{f e}=P_{h}+P_{e}
$$

Dimana :

$\boldsymbol{P}_{\boldsymbol{f} \boldsymbol{e}}=$ rugi inti (watt)

$\boldsymbol{P}_{\boldsymbol{h}}=$ rugi hysterisis (watt)

$\boldsymbol{P}_{\boldsymbol{e}}=$ rugi arus eddy (watt)

\section{1) Rugi Hysterisis $\left(\boldsymbol{P}_{\boldsymbol{h}}\right)$}

Rugi hysterisis adalah rugi yang diakibatkan oleh fluks $(\Phi)$ bolak-balik di inti besi. Pada besi yang mendapat fluks bolak-balik, Rugi hysterisis per cycle berbanding dengan luas lup (jerat) hysterisis [5]. Rugi hysterisis dapat dituliskan dalam bentuk persamaan sebagai berikut:

$$
P_{h}=K_{h} f B^{2} m
$$

Dimana:

$$
\begin{aligned}
& K_{\mathrm{h}}=\text { konstanta Hysterisis } \\
& f=\text { frekuensi }(\mathrm{Hz}) \\
& B=\text { kerapatan fluks maksimum (Tesla) }
\end{aligned}
$$

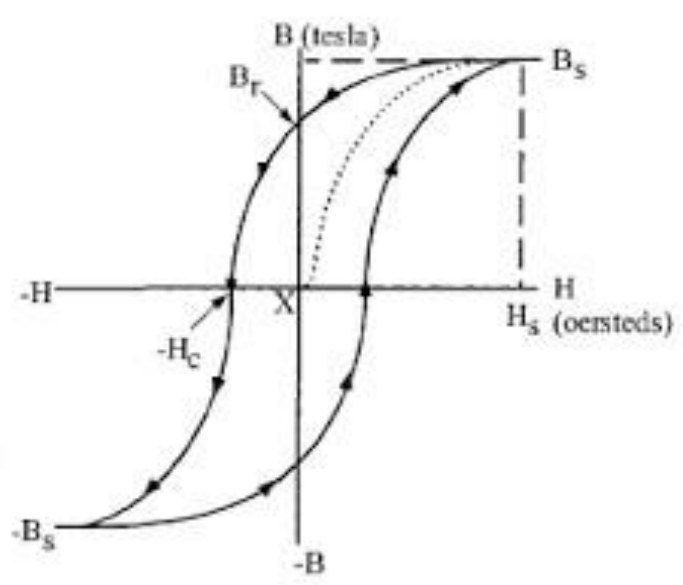

Gbr.4 Kurva Hysterisis secara umum
2) Rugi-rugi Arus Eddy

Rugi-rugi ini disebabkan pemanasan pada ketebalan inti besi oleh arus yang terinduksi pada inti dan perbedaan tegangan antara sisinya makan akan membangkitan arus yang berputar - putar pada sisi yang luas/tebal. Adanya arus eddy berdasar pada fluks magnetik yang mana perbedaan tegangan antara sisinya yang memberikan perubahan fluks tersebut. Pada dasarnya induksi tegangan di besi ini sama seperti pada trasnformator (dapat dianggap bahwa tiap lempeng besi adalah sekunder yang terhubung singkat), maka emf induksi di inti akan berbanding dengan fluks $(\boldsymbol{e}=\mathbf{4}, \mathbf{4 4} \boldsymbol{f} \boldsymbol{n}$ $\varnothing)$. Impedansi dari inti yang di aliri arus dapat dianggap konstan untuk laminasi yang tipis dan tidak tergantung pada frekuensi, untuk frekuensi rendah atau frekuensi daya listrik [6], sehingga dapat dituliskan persamaan:

$$
P_{e}=K e f^{2} B^{2} m
$$

Dimana

$\boldsymbol{K} \boldsymbol{e}$ adalah konstanta arus eddy

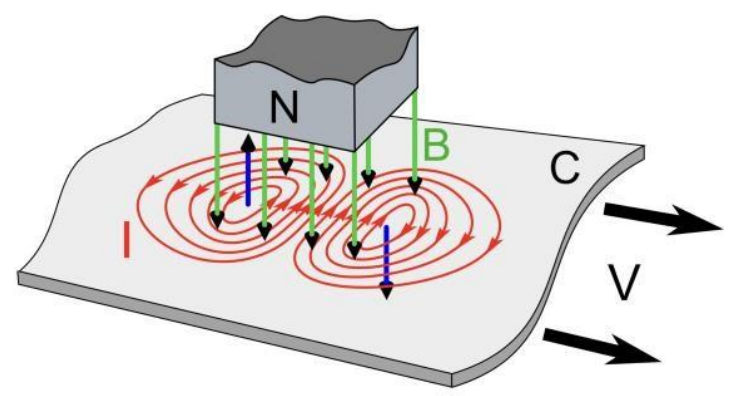

Gbr.5 Ilustrasi timbulnya arus eddy

Sehingga dari 2 bagian rugi inti didapat persamaan seperti berikut: [10]

$$
P_{f e}=P_{h}+P_{e}=K_{h} f B^{2} m+K_{e} f^{2} B^{2} m
$$




\section{METODE PENELITIAN}

Dalam menyelesaikan penelitian ini penulis membuat rancangan penelitian dengan 4 tahapan sebagai berikut:

\section{A. Studi Literatur}

Pada tahap ini, penulis mempelajari dan mengumpulkan literatur mengenai analisis analisis losses transformator. Literatur tersebut dari beberapa sumber dan referensi ilmiah, seperti buku materi analisa sistem tenaga listrik dan jurnal ilmiah, serta artikel dari website yang dapat dipertanggung jawabkan informasinya.

\section{B. Studi Bimbingan}

Pada tahap ini, penulis melakukan diskusi secara berkala dalam menyelesaikan Analisis losses transformator, sehingga penulis dapat memperoleh pengetahuan lebih dan dapat menyelesaikan tugas akhir ini.

\section{Pengumpulan dan Pengolahan Data}

Pada tahap ini, penulis melakukan pengumpulan data yang dibutuhkan, seti Single Diagram Gardu Induk Sutami, Spesifikasi perlatan penghantar sampa spesifikasi pada trafo. Kemudian data ini akan di analisis menggunakan Microsoft excel .

\section{Pembuatan Laporan}

Pada tahap ini, penulis menuliskan mengenai rencana penelitian dalam bentuk laporan proposal dan hasil dari penelitian dalam bentuk laporan akhir. Laporan ini dapat digunakan sebagai bentuk tanggug jawab penulis terhadap tugas akhir yang telah dilakukan dan digunakan untuk seminar usul dan seminar akhir.

Adapun tahapan dalam pelaksanaan penelitian ini dapat dilihat pada tabel dibawah ini:
Tabel 1. Tahapan dalam pelaksanaan penelitian

\begin{tabular}{|c|c|}
\hline No. & Keterangan \\
\hline 1. & $\begin{array}{c}\text { Menyiapkan data yang dibutuhkan } \\
\text { yaitu komponen pada Transmisi dan } \\
\text { Transformator 150 kV hingga beban } \\
\text { yang terpasang }\end{array}$ \\
\hline 2. & $\begin{array}{c}\text { Menghitung besar losses energi dan } \\
\text { losses daya pada trafo1 dan trafo } 2\end{array}$ \\
\hline 3. & $\begin{array}{c}\text { Membandingkan hasil perhitungan } \\
\text { dengan pemeliharaan pada GI } \\
\text { Sutami }\end{array}$ \\
\hline 4. & $\begin{array}{c}\text { Menghitung copper losses dan core } \\
\text { losses pada trafo 1 }\end{array}$ \\
\hline 5. & $\begin{array}{c}\text { Menghitung copper losses dan core } \\
\text { losses pada trafo 2 }\end{array}$ \\
\hline 6. & $\begin{array}{c}\text { Menentukan urutan losses tertinggi } \\
\text { pada setiap komponen }\end{array}$ \\
\hline 7. & $\begin{array}{c}\text { Menentukan persentase kenaikan } \\
\text { losses terhadap perubahan arus } \\
\text { beban puncak }\end{array}$ \\
\hline
\end{tabular}

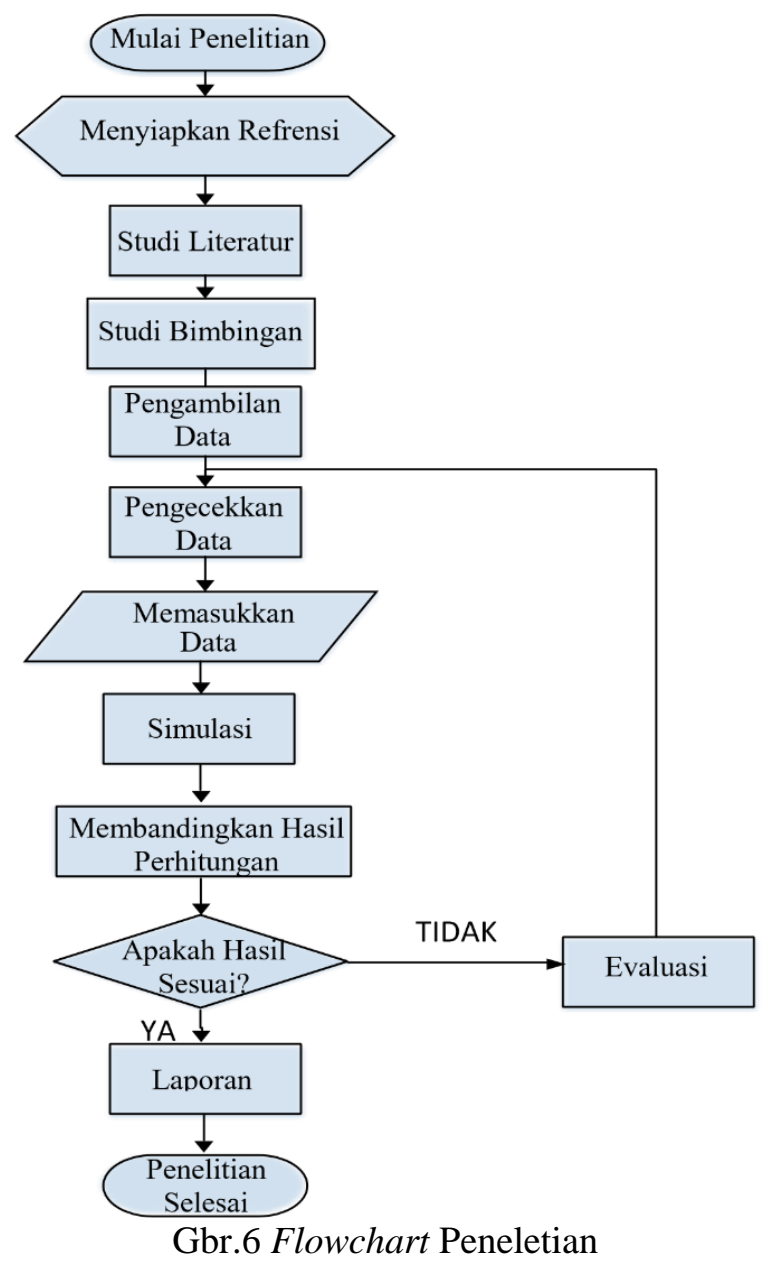




\section{HASIL DAN PEMBAHASAN}

\section{A. Analisis losses transformator}

Analisis aliran daya sangat dibutuhkan pada suatu jaringan tenaga listrik transmisi maupun distribusi. Tujuan dari analisis aliran daya antara lain untuk memperoleh nilai rugi-rugi daya pada transmisi serta nilai magnitude tegangan dan sudut fasa tegangan di setiap bus, sehingga dalam kondisi tunak dapat diketahui kondisi tegangan masih dalam toleransi atau tidak.

Selain itu, fungsi lain menghitung aliran daya pada suatu sistem tenaga listrik adalah untuk mengatur penjadwalan ulang schedule pembangkitan yang lebih efisien berdasarkan karakteristik beban. Perhitungan losses trafo dilakukan setiap hari dengan melihat selisih daya pada trafo dengan daya masuk pada penyulang.

Serta menganalisis kenaikan losses setiap harinya dan menentukan kapan losses tertinggi terjadi dengan menampilkan persentase kenaikannya.

\section{B. Data hasil losses trafo dalam satu bulan}

Dalam suatu pemeliharaan Transformator terdapat beberapa hal yang harus diukur/diuji, salah satunya pengukuran kwh energi transformator. Adapun data hasil losses transformator dibawah ini :

1) Data hasil losses trafo 1

Tabel 2. Data hasil losses trafo 1

\begin{tabular}{|l|l|c|}
\hline \multirow{2}{*}{ Penyulang } & \multicolumn{2}{|c|}{ Energi (MWH) } \\
\cline { 2 - 3 } & \multicolumn{1}{|c|}{ EXPORT } & \multicolumn{1}{c|}{ IMPORT } \\
\hline INCOMING & - & $513.892 .739,41$ \\
TRAFO 1 & $14.667 .501,39$ & \\
Baja & $116.686 .880,63$ & \\
Tembaga & $110.759 .247,90$ & \\
Emas & $40.153 .204,58$ & \\
Perunggu & $12.388 .533,12$ & \\
Nikel & & \\
Titanium & $93.625 .003,11$ & \\
Kuningan & $51.378 .203,48$ & \\
\hline TOTAL & $439.658 .574,21$ & $513.892 .739,41$ \\
\hline \multicolumn{2}{|l}{ TOTAL INCOMING TD } & $74.234 .165,20$ \\
\hline
\end{tabular}

Losses energy trafo $1=$ Incoming Trafo $1-$ Total kwh penyulang

$=513.892 .739,41-439.658 .574,21$

= 74.234.165,20 MWH

$$
\begin{aligned}
\text { Losses daya trafo } 1 & =\frac{\text { losses energy trafo } 2}{24} \\
& =\frac{342.094 .835,48}{24} \\
& =\mathbf{3 . 0 9 3 . 0 9 0} \mathbf{M W}
\end{aligned}
$$

\begin{tabular}{|c|c|c|}
\hline \multirow{2}{*}{ Penyulang } & \multicolumn{2}{|c|}{ Energi (MWH) } \\
\hline & EXPORT & IMPORT \\
\hline $\begin{array}{l}\text { INCOMING } \\
\text { TRAFO } 2 \\
\text { Besi } \\
\text { Steanlis } \\
\text { Suasa }\end{array}$ & $\begin{array}{l}\mathbf{2 7 7 . 1 3 2 . 6 3 4 , 0 0} \\
103.483 .595,39 \\
139.202 .040,35 \\
325.660 .533,25\end{array}$ & $543.752 .922,00$ \\
\hline $\begin{array}{l}\text { Perak } \\
\text { Timah } \\
\text { Platina }\end{array}$ & $\begin{array}{l}362.156 .511,00 \\
84.649 .088,02 \\
394.414 .266,00\end{array}$ & \\
\hline \multirow[t]{2}{*}{$\begin{array}{l}\text { Kabel } 2 \\
\text { PSGI }\end{array}$} & $\begin{array}{l}649.319,08 \\
1.299 .382,47 \\
532.908,96 \\
\end{array}$ & $\begin{array}{l}373.728 .814,40 \\
429.603 .706,64\end{array}$ \\
\hline & $1.689 .180 .278,52$ & $1.347 .085 .443,04$ \\
\hline \multicolumn{2}{|c|}{ TOTAL INCOMING TD } & $342.094 .835,48$ \\
\hline
\end{tabular}

2) Data hasil losses trafo 2

Tabel 2. Data hasil losses trafo 2

Losses Energy trafo 2 = Incoming Trafo $2-$ Total kwh penyulang $=1.347 .085 .443,04-1.689 .180 .278,52$ = 342.094.835,48 MWH

$$
\begin{aligned}
\text { Losses daya trafo } 2 & =\frac{\text { losses energy trafo } 2}{24} \\
& =\frac{342.094 .835,48}{24} \\
& =\mathbf{1 4 . 2 5 3 . 9 5 2} \mathrm{MW}
\end{aligned}
$$


C. Menentukan copper losses dan core losses bulanan

1) Menentukan copper losses dan core losses pada trafo 1

$$
\begin{aligned}
I_{p} & =\frac{P}{\sqrt{3 \times 150000 \times 0,8}} \\
& =\frac{74.234 .165}{\sqrt{3 \times 150000 \times 0,8}} \\
& =357 \mathrm{~A} \\
I_{S} & =\frac{P}{\sqrt{3 \times 20000 \times 0,8}} \\
& =\frac{74.234 .165}{\sqrt{3 \times 20000 \times 0,8}} \\
& =2679 \mathrm{~A}
\end{aligned}
$$

$>$ Menentukan besar copper losses

$$
\begin{aligned}
P_{c u} & =I P^{2} \cdot R_{1}+I s^{2} \cdot R_{2} \\
& =(357)^{2} \cdot 1,197+(2679)^{2} \cdot 1,426 \\
& =152.556+10.234 .460 \\
& =\mathbf{1 0 . 3 8 4 . 8 2 1} \mathbf{M W H}
\end{aligned}
$$

$>\quad$ Menentukan besar Core losses

$$
\begin{aligned}
& P_{\text {loss }}=P_{\text {copper }}+P_{\text {core }} \\
& P_{\text {core }}=P_{\text {loss }}-P_{\text {copper }} \\
& \begin{aligned}
P_{\text {core }} \quad & \mathbf{7 4 . 2 3 4 . 1 6 5}-\mathbf{1 0} \mathbf{3 8 4 . 8 2 1} \\
& =\mathbf{6 3 . 8 4 9 . 3 4 5} \mathrm{MWH}
\end{aligned}
\end{aligned}
$$

2) Menentukan copper losses dan core losses pada trafo 2

$$
\begin{aligned}
I_{p} & =\frac{P}{\sqrt{3 \times 150000 \times 0,8}} \\
& =\frac{342.094 .835}{\sqrt{3 \times 150000 \times 0,8}} \\
& =1.646 \mathrm{~A} \\
I_{S} & =\frac{P}{\sqrt{3 \times 20000 \times 0,8}} \\
& =\frac{342.094 .835}{\sqrt{3 \times 20000 \times 0,8}} \\
& =12.344 \mathrm{~A}
\end{aligned}
$$

\begin{tabular}{|c|c|c|c|c|}
\hline \multicolumn{5}{|c|}{ LOSSES ENERGY } \\
\hline \multirow[b]{2}{*}{ LOSSES } & \multicolumn{2}{|l|}{ Titik Ukur } & \multicolumn{2}{|l|}{$\%$ LOSS } \\
\hline & $\begin{array}{l}\text { TRAFO1 } \\
\text { (MWH) }\end{array}$ & $\begin{array}{l}\text { TRAFO2 } \\
\text { (MWH) }\end{array}$ & $\begin{array}{l}\text { TRAFO1 } \\
(\%)\end{array}$ & $\begin{array}{l}\text { TRAFO } \\
2 \\
(\%)\end{array}$ \\
\hline $\begin{array}{c}\text { COPPER } \\
\text { LOSS }\end{array}$ & 10.384 .821 & 259.736 .382 & 2,36 & 19,28 \\
\hline $\begin{array}{l}\text { CORE } \\
\text { LOSS }\end{array}$ & 63.849 .345 & 82.358 .454 & 14,52 & 6,11 \\
\hline $\begin{array}{c}\text { TOTAL } \\
\text { LOSS }\end{array}$ & 74.234.165 & 342.094 .836 & 16,88 & 25,39 \\
\hline
\end{tabular}

Menentukan besar Copper losses $P_{c u}=I_{P}^{2} \cdot R_{1}+I_{S}^{2} \cdot R_{2}$ $=(1.646)^{2} \cdot 1,197+(12.344)^{2} \cdot 1,684$ $=3.243 .051+256.598 .381$

= 259. 736. $382 \mathrm{MWH}$

\section{$>\quad$ Menentukan besar Core losses}

$P_{\text {loss }}=P_{\text {copper }}+P_{\text {core }}$

$P_{\text {core }}=P_{\text {loss }}-P_{\text {copper }}$

$P_{\text {core }}=\mathbf{3 4 2 . 0 9 4 . 8 3 5}-259.736 .382$ $=$ 82.358.453 MWH

Berdasarkan data hasil perhitungan diatas, data hasil copper losses dan core losses pada trafo 1 dan trafo 2 dapat dilihat pada tabel berikut :

Tabel 3. Hasil Total losses energi pada trafo 1 dan trafo 2

Berdasarkan data hasil tabel 3 total copper losses dan core losses pada trafo 1 dan 2 menunjukkan bahwa terdapat perbedaan dalam besar copper losses dan core losses. Pada trafo 2 memiliki copper losses yang lebih besar dari pada trafo 1, yaitu sebesar 19,28\%.

Hal ini disebabkan Karena selisih daya kwh trafo 2 lebih besar di banding trafo 1 yang menyebabkan kuadrat arus lebih besar.

Hal ini menunjukkan bahwa hasil perhitungan sesuai dengan teori [10], dimana besar daya berbanding lurus terhadap kuadrat arus dan resistansinya. 
D. Menentukan copper losses dan core losses harian dalam satu bulan

1) Menentukan copper losses dan core losses pada trafo 1

Tabel 4. Data hasil losses energi pada trafo 1 dalam satu bulan

\begin{tabular}{|c|c|c|c|}
\hline \multicolumn{4}{|c|}{ aаıаm saiu butan } \\
\hline DATE & $\begin{array}{l}\text { LOSSES } \\
\text { TRAFO }\end{array}$ & $\begin{array}{c}\text { COPPER } \\
\text { LOSS }(\text { KWH) }\end{array}$ & $\begin{array}{l}\text { CORE LOSS } \\
\text { (KWH) }\end{array}$ \\
\hline 01-Jul & 109.088 .688 & $22.425 .946,23$ & $86.662 .741,62$ \\
\hline 02-Jul & 108.688 .312 & $22.261 .633,66$ & $86.426 .678,74$ \\
\hline 03-Jul & 108.090 .020 & $22.017 .222,51$ & $86.072 .797,05$ \\
\hline 04-Jul & 108.087 .585 & 22.016.230,66 & $86.071 .354,22$ \\
\hline 05-Jul & 107.087 .490 & $21.610 .699,31$ & $85.476 .790,86$ \\
\hline 06-Jul & 106.087 .176 & $21.208 .849,81$ & $84.878 .326,00$ \\
\hline 07-Jul & 106.204 .485 & $21.255 .780,33$ & $84.948 .704,41$ \\
\hline 08-Jul & 109.086 .293 & $22.424 .961,42$ & $86.661 .331,15$ \\
\hline 09-Jul & 109.086.077 & $22.424 .872,69$ & $86.661 .204,06$ \\
\hline 10-Jul & 109.085 .670 & $22.424 .705,39$ & $86.660 .964,45$ \\
\hline 11-Jul & 109.091 .868 & $22.427 .253,79$ & $86.664 .614,26$ \\
\hline 12-Jul & 109.106 .256 & $22.433 .169,98$ & $86.673 .086,05$ \\
\hline 13-Jul & 106.084.995 & 21.207.977,96 & $84.877 .017,32$ \\
\hline 14-Jul & 106.084 .487 & 21.207.774,79 & $84.876 .712,34$ \\
\hline 15-Jul & 109.112 .658 & $22.435 .802,48$ & $86.676 .855,10$ \\
\hline 16-Jul & 109.083 .672 & $22.423 .883,88$ & $86.659 .787,81$ \\
\hline 17-Jul & 109.083 .335 & $22.423 .745,30$ & $86.659 .589,32$ \\
\hline 18-Jul & 109.083.185 & $22.423 .683,87$ & $86.659 .501,33$ \\
\hline 19-Jul & 109.055.712 & $22.412 .390,20$ & $86.643 .321,72$ \\
\hline 20-Jul & 108.082 .558 & $22.014 .183,02$ & $86.068 .375,35$ \\
\hline
\end{tabular}

\begin{tabular}{|l|l|l|l|}
\hline 21-Jul & 108.082 .377 & $22.014 .108,98$ & $86.068 .267,63$ \\
\hline 22-Jul & 110.081 .909 & $22.836 .168,68$ & $87.245 .739,94$ \\
\hline 23-Jul & 110.116 .890 & $22.850 .684,46$ & $87.266 .205,31$ \\
\hline 24-Jul & 110.080 .940 & $22.835 .766,97$ & $87.245 .173,43$ \\
\hline 25-Jul & 110.080 .896 & $22.835 .748,35$ & $87.245 .147,16$ \\
\hline 26-Jul & 110.080 .633 & $22.835 .639,29$ & $87.244 .993,36$ \\
\hline 27-Jul & 108.083 .432 & $22.014 .538,82$ & $86.068 .892,98$ \\
\hline 28-Jul & 108.079 .964 & $22.013 .126,39$ & $86.066 .838,08$ \\
\hline 29-Jul & 110.007 .550 & $22.805 .327,95$ & $87.202 .221,59$ \\
\hline 30-Jul & 110.079 .255 & $22.835 .067,68$ & $87.244 .187,22$ \\
\hline 31-Jul & 110.079 .047 & $22.834 .981,63$ & $87.244 .065,87$ \\
\hline
\end{tabular}

2) Menentukan copper losses dan core losses pada trafo 2

Tabel 5. Data hasil losses energi pada trafo 2 dalam satu bulan

\begin{tabular}{|c|c|c|c|}
\hline DATE & $\begin{array}{c}\text { LOSSES } \\
\text { TRAFO } \\
(\text { KW })\end{array}$ & $\begin{array}{c}\text { COPPER } \\
\text { LOSS }(\text { KW })\end{array}$ & $\begin{array}{c}\text { CORE LOSS } \\
(\text { KW })\end{array}$ \\
\hline 01-Jul & 16.010 .547 & 568.921 & 15.441 .626 \\
\hline 02-Jul & 16.021 .906 & 569.729 & 15.452 .177 \\
\hline 03-Jul & 16.033 .957 & 570.586 & 15.463 .371 \\
\hline 04-Jul & 16.053 .855 & 572.003 & 15.481 .852 \\
\hline 05-Jul & 16.054 .580 & 572.055 & 15.482 .525 \\
\hline 06-Jul & 15.859 .907 & 558.266 & 15.301 .641 \\
\hline 07-Jul & 15.875 .684 & 559.377 & 15.316 .307 \\
\hline 08-Jul & 16.048 .988 & 571.656 & 15.477 .332 \\
\hline 09-Jul & 16.225 .792 & 584.321 & 15.641 .471 \\
\hline 10-Jul & 16.236 .163 & 585.068 & 15.651 .095 \\
\hline
\end{tabular}

Volume 15, No.2, Mei 2021 


\begin{tabular}{|c|c|c|c|}
\hline 11-Jul & 16.246 .884 & 585.841 & 15.661 .043 \\
\hline 12-Jul & 16.092 .030 & 574.727 & 15.517 .303 \\
\hline 13-Jul & 15.894 .545 & 560.707 & 15.333 .838 \\
\hline 14-Jul & 15.945 .947 & 564.339 & 15.381 .608 \\
\hline 15-Jul & 16.205 .925 & 582.891 & 15.623 .034 \\
\hline 16-Jul & 16.177 .452 & 580.845 & 15.596 .608 \\
\hline 17-Jul & 16.188 .260 & 581.621 & 15.606 .639 \\
\hline 18-Jul & 16.115 .993 & 576.440 & 15.539 .553 \\
\hline 19-Jul & 16.125 .981 & 577.154 & 15.548 .827 \\
\hline 20-Jul & 15.973 .960 & 566.324 & 15.407 .636 \\
\hline 21-Jul & 15.942 .138 & 564.070 & 15.378 .068 \\
\hline 22-Jul & 16.127 .350 & 577.252 & 15.550 .097 \\
\hline 23-Jul & 16.106 .721 & 575.777 & 15.530 .944 \\
\hline 24-Jul & 16.139 .228 & 578.103 & 15.561 .125 \\
\hline 25-Jul & 16.148 .731 & 578.784 & 15.569 .947 \\
\hline 26-Jul & 16.156 .246 & 579.323 & 15.576 .923 \\
\hline 27-Jul & 16.038 .794 & 570.930 & 15.467 .864 \\
\hline 28-Jul & 16.012 .781 & 569.080 & 15.443 .701 \\
\hline 29-Jul & 16.168 .191 & 580.180 & 15.588 .011 \\
\hline 30-Jul & 16.196 .487 & 582.212 & 15.614 .275 \\
\hline 31-Jul & 16.180 .264 & 581.047 & 15.599 .217 \\
\hline
\end{tabular}

losses trtinggi jatuh pada tanggal 23 Juli 2019 sebesar 110.116.890 kwh. Copper losses tertinggi jatuh pada tanggal 23 Juli 2019 sebesar 22.850.684 kwh, dan Core losses tertinggi jatuh pada tanggal 1 juli 2019 sebesar 86.662.741 kwh.

Berdasarkan Tabel.5 Data hasil losses harian pada Trafo 2 bulan Juli 2019, menunjukkan bahwa besar hasil copper losses dan core losses relative konstan, dan besar copper losses lebih besar disbanding core losses, ini disebabkan pada trafo 2 memiliki selisih kwh yang besar, sehingga menyebabkan $I^{2} \mathrm{R}$ pada kumparan trafo menjadi semakin besar. Kemudian losses tertinggi jatuh pada tanggal 11 Juli 2019 sebesar 389.925.224 kwh, Copper losses tertinggi jatuh pada tanggal 11 Juli 2019 sebesar 337.444.543 kwh, dan Core losses tertinggi jatuh pada tanggal 13 juli 2019 sebesar 58.501.862 kwh.

E. Data hasil kenaikan losses terhadap perubahan arus normal ke arus maksimum

1) Perbandingan kenaikan losses terhadap perubahan arus beban normal ke arus beban puncak pada Trafo 1

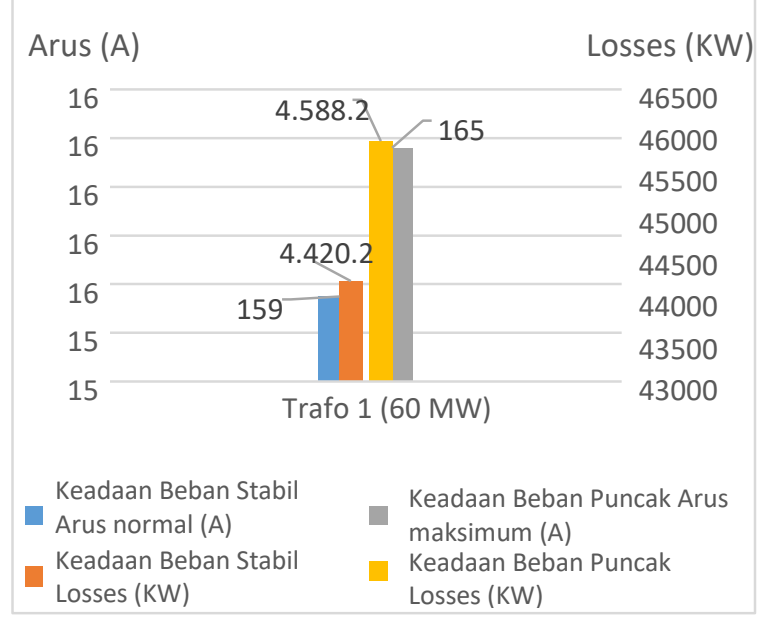

Gbr.7 Data hasil besar losses terhadap perubahan arus beban normal kearus beban puncak pada Trafo 1

Berdasarkan Tabel.4 Data hasil losses harian pada Trafo 1 bulan Juli 2019, menunjukkan bahwa besar hasil copper losses dan core losses relative konstan setiap harinya, dan pada Trafo 1 besar Core losses lebih tinggi disbanding copper losses, disebabkan selisih energi pada trafo 1 lebih kecil, menyebabkan $\mathrm{I}^{2} \mathrm{R}$ pada Trafo semakin lebih kecil. Kemudian

Berdasarkan gambar 7 menunjukkan bahwa perubahan arus pada saat beban normal ke arus pada saat beban puncak di Trafo 1 . Perubahan arus tersebut mempengaruhi besarnya rugi-rugi daya (losses) pada 
transformator. Pada saat arus normal yaitu sebesar 159,5 A memiliki losses sebesar 4.420.208 KW, sedangkan pada saat arus beban puncak yaitu sebesar 165,6 A maka losses naik menjadi 4.588.204 KW. Dari data tersebut menunjukkan bahwa perubahan arus saat beban normal, dengan arus saat beban puncak pada Trafo 1 akan meningkatkan losses sebesar $3,66 \%$.

2) Perbandingan kenaikan losses terhadap perubahan arus beban normal ke arus beban puncak pada Trafo 2

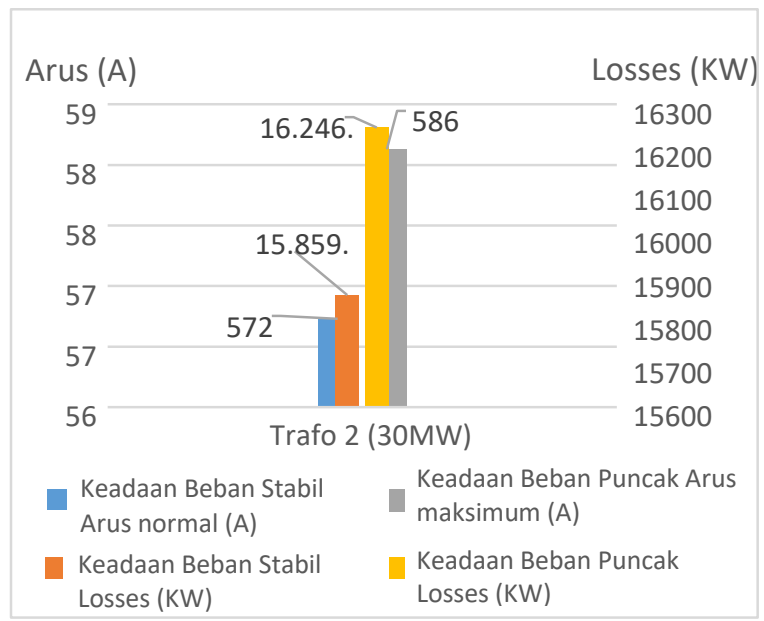

Gbr.8 Data hasil besar losses terhadap perubahan arus beban normal kearus beban puncak pada Trafo 2

Berdasarkan gambar 8 menunjukkan bahwa perubahan arus pada saat beban normal ke arus pada saat beban puncak di Trafo 2 . Perubahan arus tersebut mempengaruhi besarnya rugi-rugi daya (losses) pada transformator.

Pada saat arus normal yaitu sebesar 572,3 A memiliki losses sebesar 15.859.907 KW, sedangkan pada saat arus beban puncak yaitu sebesar 586,3 A maka losses naik menjadi 16.246.884 KW. Dari data tersebut menunjukkan bahwa perubahan arus saat beban normal, dengan arus saat beban puncak pada Trafo 2 akan meningkatkan losses sebesar $2,38 \%$.

\section{PENUTUP}

\section{A. Kesimpulan}

Kesimpulan dari hasil pemeliharaan ini yaitu :

1. Pada trafo 2 copper losses energi lebih besar disbandingkan trafo 1. Hal ini disebabkan karena pada trafo 2 memiliki losses energi yang lebih besar daripada trafo 1, yang menyebabkan $\left(\mathrm{I}^{2} \mathrm{R}\right)$ pada trafo 2 pun menjadi lebih besar. Hal ini menunjukkan bahwa hasil perhitungan sesuai dengan hipotesis sebelumnya.

2. Losses daya tertinggi pada Trafo 1 jatuh pada tanggal 23 Juli 2019, sebesar 4.588.204 kw. Copper losses tertinggi, yaitu sebesar 39.671 kw. dan Core losses, sebesar 4.548.832 kw.

3. Losses daya tertinggi pada Trafo 2 jatuh pada tanggal 11 Juli 2019, sebesar 16.246.884 kw. lalu Copper losses tertinggi, sebesar 585.841 kw dan Core losses tertinggi, sebesar $15.661 .043 \mathrm{kw}$.

4. Besar perubahan kenaikan arus dari arus beban normal ke arus beban puncak pada Trafo 1, akan menyebabkan losses naik sebesar 3,66\%. Sedangkan Besar perubahan kenaikan arus dari arus beban normal ke arus beban puncak pada Trafo 2, akan menyebabkan losses naik sebesar 2,38\%.

\section{B. Saran}

Adapun saran pada penelitian ini yaitu :

1. Pada trafo 2 sebaiknya kapasitas daya trafo ditambah, karena pada trafo 2 memiliki beban yang lebih besar, sehingga jika terjadi overload, tidak terjadi losses yang tinggi pada trafo 2 . 


\section{REFERENSI}

[1] Anthony J. Pansini, E. P. (1999). ELECTRICAL TRANSFORMERS AND POWER EQUIPMENT (3rd ed.). PrenticeHall International (UK) Limited, London: THE FAIRMONT PRESS, INC.

[2] Arifin, Zainal. 2007. Panduan Pengendalian Susut. Bandung : PT.PLN (Persero) Distribusi Jawa Barat dan Banten.

[3] Harlow, J. H. (2012). Electric Power Transformer Engineering (3rd ed.). Boca Raton London New York: Taylor \& Francis Group, LLC.

[4] Ir. Johanes Ohoiwutun, M. (2016). ANALISIS RUGI DAYA TRANSFORMATOR 100 kVA GARDU RUFEI PANTAI DI PT.PLN (PERSERO) WILAYAH PAPUA DAN PAPUA BARAT AREA SORONG. 8.

[5] J.J. Grainger and W.D. Stevenson,1994, Power System Analysis, McGraw-Hill,Inc New York.

[6] Kundur, P., 1993, Power System Stability and Control, McGraw-Hill, Inc., Toronto, U.S.A

[7] Martin J. Heathcote, C. F. (2007). The J \& $P$ Transformer Book (13rd ed.). New York.

[8] PLN. 2010. Kriteria Desain Enjinering Kontruksi Jaringan Distribusi Sistem Tenaga Listrik. Jakarta : PT. PLN (Persero).

[9] Sirait, Bonar. 2004. Diktat Kuliah Transmisi Daya Listrik Pontianak : Fakultas Teknik Universitas Tanjungpura.

[10] Siregar, N. Y. (2018). ANALISA RUGIRUGI DAYA PADA SALURAN TRANSMISI TEGANGAN $150 \mathrm{kV}$ DI PT. PLN (PERSERO) SISTEM KHATULISTIWA. 19.

[11] SPLN No. 1. 1995. Tegangan-Tegangan Standa. Jakarta : Perusahaan Umum Listrik Negara. 